\title{
SINDICALISMO AJUSTADO AO NEOLIBERALISMO: os metalúrgicos do sul fluminense
}

\author{
Gustavo Bezerra*
}

\begin{abstract}
A pesquisa investigou a trajetória do Sindicato dos Metalúrgicos do Sul Fluminense num período de conquistas, o que permitiu verificar a adoção de padrões neoliberais de comportamento mesmo sob a ausência de processos de precarização. Como resultado, o artigo apresenta um cenário sindical marcado por combatividade e atuação na cena pública da região, mas também eivado de ceticismo ante qualquer ação interlocal e intersindical. Trata-se de um sindicato potente em termos de representação direta de seus afiliados, mas que naturaliza seu viés competitivo contra outras regiões e bases sindicais. Trabalhou-se a hipótese de que a ação sindical teria sido fortemente reconfigurada por dois fatores: pelo ambiente de mobilidade dos capitais e pelo processo de normalização neoliberal dos modos de governar o território. As evidências empíricas foram recolhidas a partir entrevistas com lideranças operárias, produção acadêmica sobre a região, boletins sindicais e material jornalístico.
\end{abstract}

Palavras-chave: Sindicalismo. Neoliberalismo. Mobilidade dos capitais. Economia Regional. Escalas da ação.

\section{INTRODUÇÃO'}

Como se sabe, as relações entre sindicalismo e neoliberalismo têm sido examinadas principalmente a partir de seus efeitos, com enorme insistência sobre o tema da "precarização". No entanto, o neoliberalismo é, antes, uma técnica de governar (isto é, de conduzir politicamente a vida social), que condiciona a cidadania ao mercado, por meio de instituições pautadas pela racionalidade econômica em sentido estrito (Wacquant, 2012). Assim, não se pode confundir a análise do neoliberalismo com denúncia, identificando-o, necessariamente, com a precarização. Esse costuma ser um efeito das práticas neoliberais dos governos e das firmas sobre as multidões, mas a precarização não define o neoliberalismo. Isso fica mais evidente em períodos de ciclo econômico favorável, como o vivido pelo Brasil en-

\footnotetext{
* Universidade Federal do Rio de Janeiro. Instituto de Pesquisa e Planejamento Urbano e Regional (IPPUR-UFRJ). Av. Pedro Calmon, 550. Cidade Universitária. Prédio da Reitoria, sala 543. Cep: 21941-485. Rio de Janeiro - Rio de Janeiro-Brasil.gustavobezerra@ippur.ufrj.br

${ }^{1}$ Pesquisa realizada com o suporte material da FAPERJ, por meio do Edital de Apoio ao Desenvolvimento Científico e Tecnológico Regional (n $\left.{ }^{\circ} 33 / 2012\right)$.
}

tre 2004 e 2012, quando o avanço social da forma mercado se deu em paralelo ao avanço do poder sindical. Portanto, o objetivo aqui é evidenciar o neoliberalismo como um conjunto de crenças e procedimentos que marcam instituições e indivíduos, independentemente de questões de desempenho. A precarização está implicada na análise, mas nem tanto na forma de destituições que se avolumam linearmente do que como ameaça constante que determina formas de resistência normalizadas a um contexto neoliberal. O ponto é que, mesmo quando exitoso, tal perfil de resistências redefine as alianças inter e intraclassistas, reproduzindo uma visão de mundo mais favorável ao que caracteriza esse tipo de modelo societário: a regulação da vida social através da produção dos ambientes concorrenciais (Foucault, 2008).

O Sindicato dos Metalúrgicos do Sul Fluminense (SMSF) constitui um profícuo estudo de caso justamente por ter vivido um significativo enfraquecimento no início da neoliberalização da vida social no Brasil e, posteriormente, ter se convertido num sindicato relativamente "conquistador" de direitos e empregos. Assim, seu padrão de comporta- 
mento normalizado ao neoliberalismo (isto é, conformado à condição de agente competitivo contra outras bases sindicais) pode ser avaliado a despeito da conjuntura econômica ou da alternância dos grupos dirigentes. Outra vantagem é que o SMSF tem sido objeto recorrente de análises acadêmicas da lavra de sociólogos e historiadores. Isso contribui para uma visão de duração relativamente longa sobre ele, permitindo que se retire do Sul Fluminense uma amostra exemplar das transformações nas relações entre capital e trabalho no Brasil desde o período trabalhista, passando pela redemocratização, as privatizações e a introdução no novo paradigma das fábricas enxutas.

A questão que se impõe, sociologicamente, é: quais foram os determinantes dessa "normalização neoliberal" do SMSF desde os anos 1990? O desafio aqui é triplo:

1. qualificar esse caso de neoliberalização sindical, dando destaque à mimetização da forma empresa de atuar;

2. explicar os determinantes históricos da sedimentação desse perfil;

3. manter, não obstante, o foco na capacidade de os atores sindicais se "autodeterminarem" em função de crenças ou interesses calculados, sem também homogeneizar o grupo observado.

Na primeira seção do artigo, apresenta$\neg$ remos as hipóteses de trabalho. Na seção dois, จ o leitor acessará um breve panorama da his品 tória desse sindicato e da região. Na terceira, apresentaremos o modo como as duas linhas de força que nos servem como hipóteses explicativas - a chantagem de desinvestimento por parte de capitais móveis e o "empresariamen¿ to" da governação do território - teriam tido

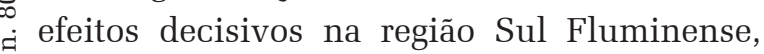
§ं influenciando não somente o comportamen$\vec{t}$ to dos dirigentes sindicais, mas sua aceitação pela própria "base". Na quarta seção, descreve-se a faceta mais combativa do SMSF, voltada ao setor siderúrgico (mais estabelecido na região), caracterizada pela luta para reduzir o potencial de "mobilidade" das empresas, em nome de não prejudicar a quantidade e a qua- lidade dos empregos no setor. A seção seguinte enfatiza o comportamento sindical frente à indústria automotiva, caracterizado pela atuação mais ajustada aos objetivos empresariais de redução de custos com o trabalho, sob a alegação de atrair novos investimentos e garantir a permanência dos projetos já conquistados.

\section{HIPÓTESES E FERRAMENTAS}

Fazer sociologia, no caso presente, será analisar como lideranças sindicais da região puderam galgar posições de poder a partir da invenção de uma variante própria do "sindicalismo de resultados". Supomos que tal posição nativa buscaria recusar, a um só tempo, tanto o sindicalismo mais confrontacionista atuante no Brasil (identificado à Central Sindical e Popular - CONLUTAS ${ }^{2}$ ) quanto o ciclo de flexibilização de direitos que caracterizara a direção sindical local nos tempos da privatização da Companhia Siderúrgica Nacional (CSN), no início dos anos 1990. Cabe situar essa dupla dissociação como um conjunto de decisões situadas num cenário bem característico da contemporaneidade, que se apresenta no Sul Fluminense de forma exemplar.

Que cenário seria esse? Em primeiro lugar, ele seria caracterizado pela ampliação das capacidades móveis dos capitais. Para Boltanski e Chiapello (2009), um dos traços do capitalismo pós-fordista é o surgimento de uma nova exploração, menos assentada no monopólio dos meios de produção que no diferencial de mobilidade: o capitalismo conexionista (estruturado sobre "redes" fugazes e reconfiguráveis) se notabilizaria pela exploração do menos móvel pelo mais móvel. A mobilidade dos capitais, segundo o modelo dos autores, possui duas dimensões. A primeira delas é a espacial, baseada na capacidade de os agentes capitalistas ameaçarem trabalhadores e agen-

${ }^{2}$ A CSP - CONLUTAS é uma central sindical criada em 2010, considerada um "racha à esquerda" da Central Única dos Trabalhadores. 
tes territoriais "conflitivos" com o deslocamento de seus investimentos para outros lugares ou atividades lucrativas. A outra mobilidade seria “organizacional”, caracterizada por práticas organizativas renovadas, como os círculos de qualidade e a customização do salário, que paralisam as formas tradicionais de resistência à exploração, na medida em que alteram os critérios de "sucesso" e "fracasso" pelos quais trabalhadores e críticos da acumulação costumavam se pautar.

Como segundo determinante da normalização neoliberal da ação do SMSF, trabalharemos a hipótese da disseminação de técnicas empresariais de governação do território, que visariam primordialmente à criação de um bom "ambiente de negócios" e à geração de receitas no local. O empresariamento da gestão territorial estaria sendo propugnado a partir de diversas fontes: as próprias administrações públicas, as empresas, as entidades patronais e as instituições de ensino, para mencionar as principais. Tal rede de "governamentalidade" neoliberal busca, nos planos simbólico e prático, condicionar a cidadania ao ajustamento de indivíduos, coletividades e territórios à lógica de mercado. Buscaremos situar as tomadas de posição dos dirigentes sindicais atuais nos marcos dessa dupla adversidade (a mobilidade dos capitais e o empresariamento das administrações públicas), não para reificar a posição "amigável" do sindicato ao capital como a única possível, mas, ao contrário, para chamar a atenção para os elementos que têm obstado a emergência de práticas sindicais mais críticas.

Supomos que a relação do SMSF com as centrais sindicais pouco elucida as razões pelas quais ele mantém a "parceria" com as empresas como diapasão. Menos ainda é capaz de explicar uma dimensão não parceira que subsiste, a saber, contra o seu principal contendor histórico, que é a CSN. Veremos que o SMSF tem se mostrado relativamente amigável às montadoras de automóveis, mas afirmando uma postura de "confronto" contra a CSN.

Essa postura bifronte por parte do sin- dicato merece ser explicada. Em termos de resultados de pesquisa, afirmaremos que ela reflete a leitura da situação em dois campos de relações sociais:

1. a interação com um campo sindical nacional, vinculado à indústria automobilística, a partir do qual o SMSF "aprendeu" que os sindicatos mais confrontacionistas teriam perdido força ao afugentar novos investimentos;

2. há um "aprendizado confrontacionista" no seu velho bastião siderúrgico, arena na qual se observam vantagens práticas e simbólicas na marcação cerrada sobre uma CSN gerida por Benjamim Steinbruch, empresário considerado "perverso" e sem compromisso com os habitantes da região (o que será detalhado mais adiante). ${ }^{3}$

Há nove anos, o grupo que gravita em torno de Renato Soares (atual vice-presidente do SMSF, que o presidira nas duas gestões anteriores) articula estrategicamente aqueles dois eixos simultâneos de ação, num claro exemplo, quando se engaja na atração de novas empresas e postos de trabalho para a região. Por essa estratégia, o sindicato busca aumentar, justamente, sua autonomia frente à CSN (que anteriormente quase monopolizava a condição de empregadora). Tal dinâmica, que vem aumentando a importância de cidades como Resende e Porto Real, verdadeiramente regionaliza um sindicato historicamente polarizado em Volta Redonda, ${ }^{4}$ que configurava um dos mais exemplares casos de "sindicalismo de cidade-empresa” (Pereira, 2012) que se tem notícia. Nessa estratégia de articulação das escalas próximas e distantes, o grupo dirigente também se demarca da oposição sindical no Sul Fluminense ao capitalizar "vitórias" nas escalas em jogo, embora não sem receber críticas dos grupos sindicais concorrentes no local e em

${ }^{3} \mathrm{O}$ que veremos no item "Momentos de resistência aos deslocamentos dos capitais: um confrontacionismo corporativista".

${ }^{4}$ Durante muito tempo, aliás, a organização se chamava Sindicato dos Metalúrgicos de Volta Redonda (SMVR), embora representasse também metalúrgicos de cidades vizinhas. 
outras regiões candidatas a investimentos do setor automotivo.

Diremos que a diretoria do SMSF tem orientado o seu comportamento por duas estratégias complementares: uma "confrontação corporativista" com relação às empresas siderúrgicas e um "insulamento competitivo" no que diz respeito ao setor automotivo. Seriam estratégias complementares, a despeito de seus sentidos opostos, na medida em que convergem para um mesmo saldo "positivo" (obtenção de direitos e empregos), mas em termos particularistas apenas. Se considerarmos a concepção de "classe trabalhadora" que o SMSL tinha latente nos anos 1980, típica do período da redemocratização no Brasil, o comportamento atual do sindicato representa um duplo recuo:

1. veremos que há pouca solidariedade com os vendedores de força de trabalho de outras partes, quanto mais no próprio segmento dos metalúrgicos, que deixam de ser "companheiros" para serem vistos como "concorrentes";

2. do ponto de vista local, também foram erodidos os laços de outrora com movimentos comunitários e com outros sindicatos da região.

Assim, o artigo busca explicar como o SMSF reconfigurou sua capacidade de representar os interesses de sua base sindical deA pois da privatização da CSN, mas renuncianNo à ideia de classe trabalhadora e aceitando $\stackrel{\infty}{\infty} 0$ o arrazoado de que os direitos (do trabalho e da cidadania urbana) devem estar condicionados às necessidades de mercado. Se parte do ativismo sindical dos anos 1990 e 2000 buscou resistir ao neoliberalismo através da controversa invenção de um "sindicalismo cidadão" (Oliveira, 2011), voltado para a criação de espaços públicos e solidariedades contra os particularismos de mercado, veremos os metalúrgicos do Sul Fluminense agirem de modo mais conformado (prática e simbolicamente) à "necessidade" de tornar a sua ação atrativa aos investidores.

\section{O SINDICATO ANTES DA DÉCADA DE 1990}

O SMSF possui a peculiaridade de pertencer ao "berço" da industrialização brasileira. Seu nascimento se deu a partir do primeiro "grande projeto" de desenvolvimento no Brasil, impondo ao sindicato a contingência de se constituir a partir de um território de ocupação acelerada e massificada. Ao mesmo tempo, sua estruturação se fez de um modo peculiarmente controlado pelo Estado, o que pode ser atestado pela significativa presença de militares na condução da Companhia Siderúrgica Nacional e da própria Company Town de Volta Redonda. A capacidade estatal de tutelar a ação sindical na região foi durável. A primeira greve da história da Companhia Siderúrgica Nacional foi realizada em reação ao golpe de 1964, sendo severamente reprimida, inclusive com a demissão de algumas lideranças metalúrgicas que haviam comparecido ao comício de João Goulart na Central do Brasil semanas antes.

A tutela estatal também explica por que somente em 1984 ocorreu nova greve dos metalúrgicos da região, num claro hiato temporal frente à emergência nacional de um Novo Sindicalismo, que fazia do "grevismo" um componente da afirmação de sua identidade antiditatorial e basista. É verdade que a repressão não explica sozinha a relativa paz; a ação sindical local também tinha um histórico formidável de obtenção de direitos. De toda forma, sublinhe-se que esse sindicato continuava a atuar sob condições especiais, pois Volta Redonda permaneceu como território de "Segurança Nacional” até meados 1985.

Por essa mesma condição sui generis é que se deve avaliar o significado das greves anuais massificadas de 1984 a 1988, que mobilizaram não somente uma categoria laboral, mas o conjunto da cidade de Volta Redonda em confrontos violentos com o Exército (Santana, 2006). Em 1988, os meios de comunicação brasileiros deram amplo destaque a um movimento grevista espetacular, não só por suas 
dimensões, mas também pelo dramático caso da invasão militar na Usina Presidente Vargas, que resultou na morte de três operários. Mesmo assim, o sindicato obteve conquistas significativas, como o turno de seis horas de trabalho e, no mesmo ano, levou a sua principal liderança sindical a vencer as eleições para prefeito.

O período desenvolvimentista brasileiro havia legado a Volta Redonda e a seu entorno, portanto, um caráter escalar eminentemente "nacional". Desde sempre, o aço produzido localmente fazia parte de uma geoestratégia de sustentação da Indústria brasileira a partir da oferta de matérias-primas baratas. Assim, a usina estava longe de ter uma gestão "empresarial" plena, na medida em que sequer estava voltada ao imperativo de "pagar a si própria". Quando a economia nacional se viu combalida pela crise da dívida externa nos anos 1980, o ativismo sindical do Sul Fluminense acabaria por ser objeto de uma forte ofensiva por parte direção da companhia. Como se tratava de uma empresa estatal, tentava-se não somente arrefecer o ânimo de um sindicalismo reivindicativo, mas também buscar dobrar o ativismo sindical resistente à ideia de se privatizar a CSN.

\section{A CONVERSÃO DO SUL FLUMI- NENSE AO IDEÁRIO EMPRESA- RIAL: mobilidade dos capitais e em- presariamento da gestão territorial}

A propósito de explicar a durabilidade da estratégia de insulamento competitivo (isto é, de apartação e competição contra outros sindicatos) adotada pelo SMSF, que será detalhado na seção cinco deste artigo, cremos ser necessário situar as transformações nas relações sociopolíticas do Sul Fluminense como um todo. Tais transformações constituem um caso particular (e exemplar) do fenômeno mais geral de reconfiguração das relações entre capital, trabalho, Estado e território na contemporaneidade.

Na França, há, pelo menos, duas cor- rentes sociológicas voltadas para explicar o enfraquecimento das lutas contra a exploração e a mercantilização da vida, sob o ocaso da sociedade fordista. Uma enfatiza as coerções impostas diretamente por capitais móveis que se deslocaram em relação aos dispositivos de regulação típicos da era fordista ${ }^{5}$, enfraquecendo agentes sociais que pressionavam pela democratização da riqueza e das tomadas de decisão. A outra focaliza o papel do Estado, que teria sido capturado por um campo burocrático renovado, recém-convertido ao ideário neoliberal. A primeira corrente é a de Boltanski e Chiapello, desenvolvida no livro O Novo Espírito do Capitalismo (2009). A segunda pode ser identificada a Bourdieu (1998) e Wacquant (2012). Passar em revista os dois modelos explicativos será útil para a elucidação do caso do Sul Fluminense, o qual, supomos, só pode ser explicado pela combinação de ambas as dinâmicas.

Boltanski e Chiapello (2009) argumentam que o mundo vive uma era de capitalismo conexionista, caracterizado pela profusão de "microdeslocamentos" organizacionais e geográficos (rumo a lugares onde a crítica social é mais frágil). Com os deslocamentos, grandes empresas buscariam renovar as formas de realização dos lucros, esquivando-se de pressões sociais (leis, normas, protestos, greves etc.) voltadas para a repartição da renda e do poder decisório. Seriam fatos localizados e fragmentários, capazes de desbaratar o controle social baseado na voz de agentes. ${ }^{6}$ Os deslocamentos potenciais instaurariam um tipo específico de exploração, referente a um capitalismo estruturado em redes reconfiguráveis. Isso porque

${ }^{5}$ Segundo Castel (1998), as sociedades fordistas ou salariais seriam formações histórico-espaciais que fizeram da expansão das relações de assalariamento um mecanismo de distribuição do produto social da acumulação capitalista e o principal dispositivo da coesão social. Os dois principais expedientes sobre os quais esse tipo de sociedade teria se assentando seriam a organização dos trabalhadores por grupos homogêneos e o Estado Social.

6 "É preciso evitar ver nos deslocamentos o resultado de uma estratégia de conjunto, elaborada em instâncias secretas e aplicadas de cima para baixo. Eles não são interpretáveis em termos de plano preconcebido, planificado, organizado por um ator onisciente e onipotente - patronato ou capitalismo - nem em termos de processo inconsciente, sem sujeito e sem reflexão" (Boltanski; Chiapello, 2009, p. 499). 
“[...] cada um vive a angústia permanente de ser desconectado, ficar entregue à própria sorte, abandonado no local por aqueles que se deslocam” (Boltanski; Chiapello, 2009, p. 373). Assim, tratar-se-ia da exploração do mais móvel sobre o menos móvel, facultada pelo medo do mais fraco de ser desconectado da rede.

A segunda chave interpretativa enfatiza a grande capacidade de coordenação do Estado sobre as práticas de difusão material e simbólica da forma mercado ou mercadoria. Para Wacquant (2012, p. 507) trata-se do fenômeno da "reestruturação do Estado como principal agência que conforma ativamente as subjetividades, as relações sociais e as representações coletivas apropriadas a tornar a ficção dos mercados real e relevante”. Isso se daria a partir da colonização ideológica entre os gestores do Estado, do projeto de imposição da marca do mercado sobre a cidadania. Essa chave, menos centrada na acumulação de capitais que no neoliberalismo como regime político, situa a debacle do pacto social fordista nas transformações do campo burocrático ${ }^{7}$ o qual produz e reproduz os quadros pensantes no Estado. O autor argumenta que essa consagração da “mão direita do Estado" (a dimensão "econômica, que pretende impor restrições fiscais e a disciplina de mercado") sobre a "mão esquerA da" (a dimensão "social, que protege e apoia as จे categorias destituídas de capital econômico e cultural”) não teria sido produto de qualquer imperativo sistêmico ou mesmo de necessidades econômicas funcionais: ela seria o resultado de batalhas simbólicas e materiais dentro e fora do campo burocrático internacional.

No caso dos agentes do Sul Fluminense, é possível ver tanto as ameaças de deslocamento de capitais quanto a difusão de uma $\Rightarrow$ concepção empresarial de Estado como forças indutoras de um cenário que introverteu as lutas por justiça social naquele território, em

7 "Sustento que o conceito pouco conhecido de Bourdieu (1994) de campo burocrático oferece uma ferramenta flexível e poderosa para compreender a reconstrução do Estado como máquina de estratificação e classificação, que está orientando a revolução neoliberal a partir de cima" (Wacquant, 2012, p. 510). favor da causa da competitividade e da eficiência produtivas. Buscaremos reconstituir alguns desses lances principais, que teriam tido efeitos duradouros sobre o Sindicato dos Metalúrgicos da região.

O que determinaria uma primeira redefinição das condições sociais de enfrentamento do SMSF com o governo, até então o seu “patrão”, foi a própria crise da dívida externa brasileira, com a concomitante ameaça de exclusão do Brasil do mercado internacional de crédito. É preciso ver como essa fuga das oportunidades de lucro em direção às finanças instaurou paulatinamente um regime de dominação de novo tipo, ${ }^{8} \mathrm{com}$ a sua cor local (e exemplar) no Brasil e com imediatas consequências em Volta Redonda e seus arredores. De modo elucidativo para o caso em tela, Boltanski e Chiapello (2009, p. 375) destacam que:

\section{[...] os mercados financeiros deslocam seus investi- mentos num ritmo que não tem termo de comparação com as trocas de mercadorias [...] eles são os primei- ros exploradores (porque são os mais móveis) de uma longa cadeia de exploração em cascata. Sua lógica de atuação incentiva suas vítimas, quando possível, a tornar-se tão flexível quanto os capitais [...].}

Como alhures, no Brasil a dependência de capitais externos voláteis tirou a legitimidade do Estado desenvolvimentista e do seu desenho institucional, concomitantemente ao fortalecimento da legitimidade da segunda linha de força, a saber, do ideário neoliberal. O setor siderúrgico foi um dos primeiros a se tornar alvo dos interesses na abertura e na privatização crescente da economia brasileira. Essas medidas passaram a ser acolhidas mesmo por quadros de governo formados no desenvolvimentismo tradicional. O governo Sarney chegaria a privatizar quatro siderúrgicas de médio e pequeno porte entre 1988 e 1989 (Pereira, 2012, p. 194).

${ }^{8}$ Chesnais (2003) enfatiza a hegemonia das finanças como um regime de "dominação social" mais amplo, ou seja, um modo de dirigir a ação dos agentes econômicos e políticos. Harvey (2005) também observou o papel da financeirização na imposição de uma nova onda de aceitação dos aspectos mais predatórios do capitalismo contemporâneo. 
Assim, não foi surpreendente que, no contexto greve de 1988, o ministro da Indústria e Comércio propusesse ao presidente Sarney a possibilidade de privatização da CSN por conta "dos prejuízos de 40 milhões de dólares com os oito dias greve”. O ministro avisou também à imprensa que o governo discutiria "em breve a possibilidade de desativação parcial ou total da CSN” (Jornal do Brasil apud Graciolli, 2007, p. 209). Como se vê, a greve já não era só confrontada a partir do dispositivo militar-judiciário tradicional, mas pela ameaça de desemprego e de depressão econômica regional. As ameaças de deslocamento dos capitais haviam efetivamente criado efeitos de exploração e de sujeição em cascata: era o próprio governo federal, premido pelo imperativo da "reengenharia” voltada a pagar juros ao capital financeiro, que ameaçava com o fechamento da CSN caso a greve não cessasse e os trabalhadores não aderissem à privatização e ao "empresariamento" da estatal.

As ameaças de imposição estatal de contextos de escassez econômica continuaram nos lances seguintes: a ameaça de fechamento da empresa foi acionada para obrigar os trabalhadores a concordarem com diversas medidas, como o "saneamento" da empresa, a derrota de um setor sindical "confrontacionista" frente a uma chapa francamente a favor da privatização e, por fim, com a privatização propriamente dita, em 1993. ${ }^{9}$ Apenas entre 1989 e 1991 (não por acaso o contexto que se seguiu à mais monumental das greves), a CSN demitiu cerca de 6.300 trabalhadores (Pereira, 2012, p. 273). Nesses anos de saneamento, houve significativo aumento da população residente em condições urbanas precárias (Lima, 2010), completando um quadro de profunda resignação quanto às lutas por justiça social nessa cidade operária que outrora atraíra militantes

${ }^{9}$ Em 1990, chegaria à CSN uma nova direção especialmente designada para promover um "saneamento" profundo na empresa, que, caso fracassasse, deveria fechá-la em 90 dias (Graciolli, 2007, p. 121-122). O novo presidente da companhia fez um discurso fortemente antissindical em sua posse, ameaçando com milhares de demissões, o não pagamento de dias parados em caso de greve e a perspectiva da privatização. de vários cantos do Brasil. ${ }^{10} \mathrm{O}$ caso da vitória da chapa da Força Sindical, em 1992, passou pela clara interferência do presidente da companhia ainda estatal, que proferiu um discurso dentro da CSN ameaçando os trabalhadores com demissões em massa. O fato reverteria a desvantagem da chapa da Força Sindical diante do grupo "confrontacionista" que tinha o triplo das intenções de votos até então. ${ }^{11}$

Ressalte-se, porém, que não apenas dispositivos de coerção foram usados nesses episódios voltados para tornar o sindicato e a cidade mais afeitos à razão empresarial. Também se lançou mão de diversos dispositivos de cooptação na forma do que Boltanski e Chiapello (2009) chamam de "deslocamentos organizacionais" (quando há transformações nos critérios de classificação e de "sucesso" numa empreitada capitalista). Por exemplo, houve a "financeirização" de parte da renda de operários e aposentados, a partir da ideia de que isso representaria a verdadeira "participação dos trabalhadores na empresa". O clube de investimentos dos operários, que participou da compra da empresa, chegou a contar com 28 mil associados. Também o proeminente Sindicato dos Engenheiros de Volta Redonda (SENGE-VR), crítico da privatização e vinculado à CUT, acabaria formando um clube de compra de ações.

Após a privatização, novos deslocamentos locacionais e organizacionais enfraqueceram o SMSF e a prefeitura de Volta Redonda frente à CSN. Destaque-se o fato de a empresa ter deslocado parcialmente seu foco da siderurgia para a exportação de minério de ferro ${ }^{12}$ e usar esse processo para pressionar os trabalhadores da Unidade Presidente Vargas (UPV),

${ }^{10}$ Segundo uma militante dos movimentos urbanos entrevistada pela pesquisa, Volta Redonda teria chegado a contar com cerca de mil militantes "profissionais" no final dos anos 80 , que circulavam entre diferentes movimentos populares e sindicais na cidade.

11 "Falei que meu candidato era Forca Sindical, botei o candidato ao lado, expliquei que a CSN não aguentava ficar com essa guerra trabalhista [...] esse era o problema dos empregos deles, eu tinha emprego. Foi bem assim, foi bem rasgado mesmo" (Lima Neto apud Pereira, 2012, p. 240).

${ }^{12}$ A partir da exploração da mina de Casa de Pedra, na cidade de Congonhas (MG). 
afirmando que o aço já não seria tão atrativo. Além disso, a CSN deslocou parte significativa de seu quadro administrativo para São Paulo, após litígio com a prefeitura em torno do imposto territorial urbano, mantendo desocupado seu edifício de 16 andares (o maior da cidade), situado em aérea estratégica da cidade do aço (Góes, 2013).

Em meados dos anos 1990, o Sul Fluminense se encontrava em depressão econômica e repleto de incertezas. Não somente em função da queda da renda e do emprego em Volta Redonda. Resende também passava por um processo de evasão de capitais que haviam se deslocado para regióes onde pudessem contar com isenções tributárias (Lima, 2006), num cenário de particular aguçamento da guerra fiscal no Brasil. De toda a forma, a região estava bem situada do ponto de vista dos mercados e da logística nacional, contando com força de trabalho e aparatos de formação profissional preciosos. Tão importante quanto esses fatores, o território abrigava grupos empresariais e quadros técnicos com bons laços sociais no exterior e em diferentes esferas governamentais. Assim, essa região dotada de recursos teve sucesso em "sair à caça” de novos investimentos, tendo destaque o setor automotivo. O Quadro 1 sumariza essa chegada de greenfields automobilísticos.

A atuação do SMSF quando da chegada das primeiras montadoras já foi bem coberta pela pesquisa acadêmica. Os trabalhos puderam demonstrar que a privatização da CSN não fez terra arrasada da atividade sindical na região, sendo mais pertinente considerar sua "reconfiguração" a partir da consolidação do eixo automotivo entre Resende, Itatiaia e Porto Real. Essa nova "região dentro da região" acabaria até ganhando a alcunha de "RIP", para designar as cidades de um alegado "ABC Fluminense" (Durão, 2011), que agora concorreria com o ABC paulista. Vê-se que o sindicato teve o eixo geográfico do crescimento de seus representados alterado, necessitando também diversificar pautas para além da siderurgia.

Ainda na década de 1990, chegou ao Sul Fluminense uma das experiências mais limítrofes de reestruturação produtiva (Francisco, 2012), a saber, o "consórcio modular" da Volkswagen/MAN de fabricação de caminhões. Mesmo assim, a ação sindical mostrou sua capacidade reivindicativa: fez-se daquela

Quadro 1 - Competição por montadoras envolvendo o sul fluminense

\begin{tabular}{|c|c|c|c|c|}
\hline Empresa & $\begin{array}{l}\text { Investimentos } \\
\text { anunciados }\end{array}$ & $\begin{array}{l}\text { Territórios que disputa- } \\
\text { ram a implantação }\end{array}$ & $\begin{array}{l}\text { Número de em- } \\
\text { pregos direitos e } \\
\text { indiretos }\end{array}$ & Decisão final \\
\hline $\begin{array}{l}\text { Volkswagen/MAN* } \\
\text { (caminhões) }\end{array}$ & U\$ 300 milhões & $\begin{array}{l}\text { ABC paulista (SP) } \\
\text { Resende (RJ) }\end{array}$ & 900 a 1.500 & Resende (RJ) \\
\hline Peugeot** & $\begin{array}{l}\text { US\$ } 600 \text { milhões } \\
(2002) .\end{array}$ & $\begin{array}{l}\text { Porto Real (RJ) } \\
\text { Resende }\end{array}$ & 2.000 & Porto Real (RJ) \\
\hline Nissan *** & R\$ 2,6 bilhões & $\begin{array}{l}\text { "Interior paulista” (SP) } \\
\text { São José dos Pinhais (PR) } \\
\text { Resende }\end{array}$ & 2.000 & Resende \\
\hline Fóton (caminhões) $* * * *$ & 250 milhões & $\begin{array}{l}\text { Itatiaia (RJ) } \\
\text { Seropédica (RJ) } \\
\text { Guaíba (RS) }\end{array}$ & 450 & Guaíba \\
\hline Toyota***** & US\$ 750 milhões & $\begin{array}{l}\text { Sorocaba (SP) } \\
\text { Resende } \\
\text { Guaíba }\end{array}$ & 2.500 & Sorocaba \\
\hline Jaguar/ Land Rover $* * * * * *$ & R\$ 750 milhões & $\begin{array}{l}\text { Resende } \\
\text { Itatiaia }\end{array}$ & 500 a 700 & Itatiaia (RJ) \\
\hline \multicolumn{5}{|c|}{ 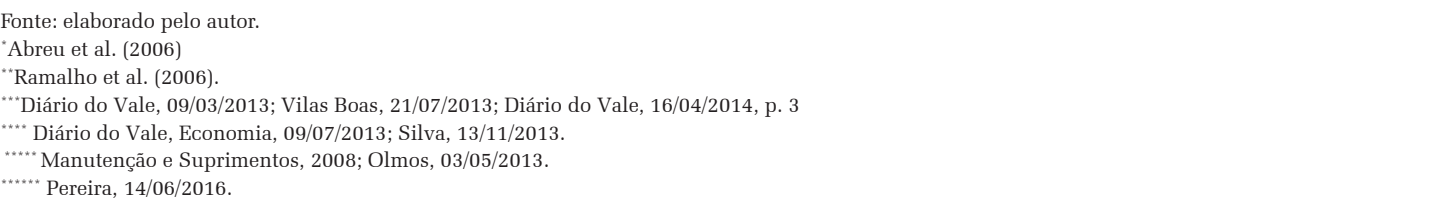 } \\
\hline
\end{tabular}


planta a primeira a parar durante um "festival de greves" realizado no setor automotivo nacional (num momento de fecunda unidade entre CUT e Força Sindical), no final de 1999 (Cardoso, 2006). Em meados daquela década, o recém-criado município de Porto Real recebeu uma unidade da Peugeot-Citroen, empreendimento ainda mais impactante no território. Nos últimos anos, o sindicato espraiou o escopo de sua atuação para além das condições de trabalho, contrato e remuneração, passando a atuar em esferas mais propriamente vinculadas ao "desenvolvimento" da região, como o "Fórum Demissão Zero" e o "Mercovale" (Ramalho, 2012), porém "em parcerias" mais próximas do empresariado do que de setores populares.

O desenvolvimento de uma gestão territorial neoliberal pode ser apontado como um segundo eixo determinante da transformação durável do SMSF numa vertente do sindicalismo de resultados. O quadro de ameaça permanente de evasão de capitais vem sendo objeto de tratamento governamental neoliberal não menos constante. Em todo caso, "governo" aqui não deve significar apenas Estado, mas, principalmente, um modo neoliberal de imbricar Estado e sociedade civil na disseminação da forma mercado. Ora capitaneados por agentes públicos, ora por atores empresariais (especialmente do Sistema FIRJAN), as iniciativas têm em comum a importação para o Sul Fluminense do ideário de planejamento territorial pós-fordista, voltado para o "desenvolvimento endógeno” (sem ajuda do governo federal).

Harvey (1996, p. 50) caracterizou esse novo planejamento localista, fragmentário e competitivo. O mais importante nesses planos e práticas seriam suas intenções, o sentimento genérico que provocam, atingindo subjetividades, desencadeando processos em que a dimensão simbólica é acionada para construir o "bom clima de negócio". A pretensão de trazer à sociedade uma visão diferente dos atores do mercado também seria seu componente fundamental. À diferença do planejamento que se consagrou no mundo pós-guerra, segundo o qual se planejava para corrigir os efeitos do mercado, busca-se agora creditar à iniciativa econômica privada uma significativa parcela de responsabilidade na solução dos problemas urbanos, regionais e ambientais. Dado esse quadro cognitivo, três seriam os principais efeitos da nova "governança" territorial: a celebração das parcerias público-privadas; o caráter especulativo da intervenção estatal (que promove intervenções urbanas na expectativa de que investidores privados as aproveitem); e o maior foco na "economia política do local" do que no território. O governo novo das territorialidades flerta com a democracia na medida em que deixa de ter o perfil impositivo, mas também deixa de ter por referência os conflitos entre capital e trabalho na cidade e a reforma urbana de modo mais geral. Sintoma disso seria o esvaziamento de dispositivos como os planos diretores municipais em favor dos planos estratégicos voltados para atrair empresas.

O MERCOVALE, consórcio regional de prefeituras, que vigorou entre meados dos anos 1990 e 2000, deu testemunho da força desse ideário de planejamento no Sul Fluminense. Ainda que o consórcio tenha adotado uma versão light do planejamento competitivo, na medida em que buscou ao menos minimizar a concorrência entre as próprias administrações públicas municipais (propugnado o ISS único e subscrevendo carta-compromisso conjunta à Peugeot-Citroen), não se pode minimizar o quanto essa maneira de conceber o desenvolvimento rompia com as práticas correntes. Nos anos 1980, Volta Redonda e Resende estiveram marcadas por significativas lutas e conquistas no tema da reforma urbana (Cardoso, 2012; Souza, 1992), mas elas foram significativamente negligenciadas nas iniciativas pelo "desenvolvimento" a partir da década seguinte, inclusive por parte das administrações públicas. O pensamento dos quadros públicos regionais foi sendo crescentemente formado pelos quadros privados:

O Grupo Consultor, composto pela Andersen Consulting - e depois pela KPMG, e pelas empresas 
Agência 21 e Dialog, passaria também, a defender uma concepção do MERCOVALE na qual o acento recaía na atratividade, a partir da qual uma identidade competitiva seria gestada e tornar-se-ia predominante, potencialmente esvaziando a dimensão política das ações e estratégias regionais (Santos, 2007, p. 104).

Num lance ainda mais emblemático desse empresariamento da gestão pública, registre-se que a própria marca comercial do MERCOVALE passaria a ser disputada por diferentes consultorias (Santos, 2007). No refluxo dessa iniciativa liderada pelos secretários municipais de desenvolvimento, a FIRJAN organizou o Arranjo Produtivo Local (APL) do setor metalomecânico da região. Por essa iniciativa, buscava-se reforçar a formação de mercados e a mediação de dinâmicas municipais e estaduais de atração empresas. Além disso, organizou-se a disseminação de instituições de ensino cada vez mais atreladas às empresas instaladas (inclusive com cursos surgidos "dentro" das montadoras), redefinindo, na região, os expedientes de produção de uma força de trabalho fabril relativamente cativa, inclusive nos postos de comando. Conforme ponderou o trabalho acadêmico de Cordeiro (2012, p. 193 ), “Quais são as possibilidades de emprego do diplomado em Engenharia de Produção Automotiva fora do Polo automotivo?".

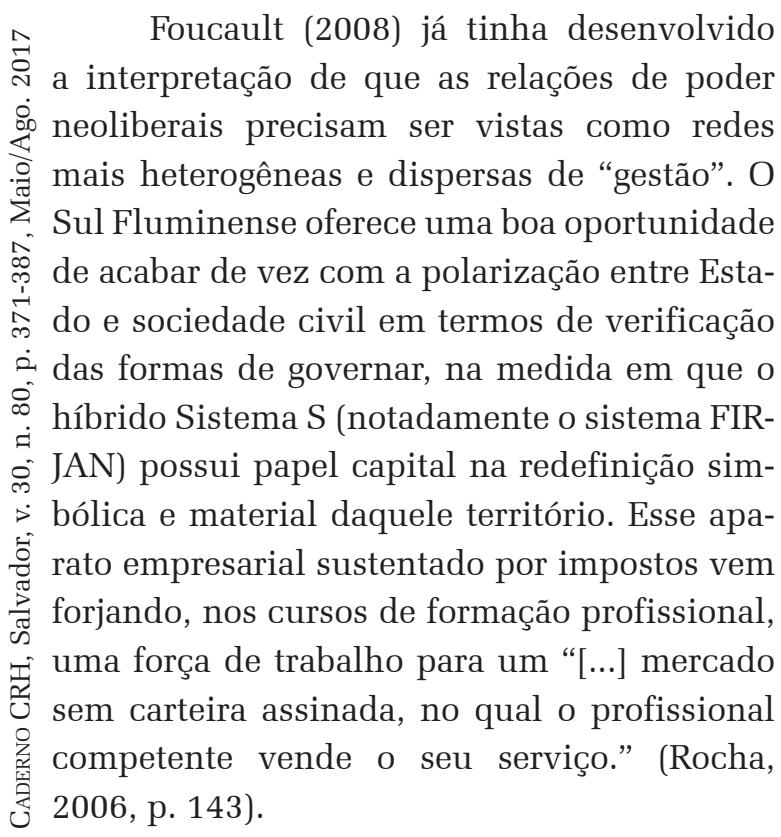

\section{MOMENTOS DE RESISTÊNCIA AOS DESLOCAMENTOS DOS CAPITAIS: um confrontacionismo corporativista}

A presente seção não vai aprofundar ainda os traços neoliberais que atribuímos à ação sindical do SMSL. O item pretende marcar o quanto tal qualificação não busca designar um sindicalismo acrítico ou complacente com as empresas. Veremos um sindicato combativo, porém, com o limite de defender apenas a sua própria base de representação formal e que, se "necessário", age competitivamente contra outros sindicatos metalúrgicos. O trecho ajuda a compor a conclusão de que a neoliberalização do sindicato (determinada pelo contexto de exploração via mobilidade e pela atuação de um "Estado empresário") se converteu numa forma inovadora de realizar um velho sonho: o projeto corporativista, típico dos anos 1930, de produzir um sindicato que luta pelos interesses de uma base particular, mas que recusa uma conflitividade mais articulada entre capital e trabalho.

Enfrentamos a CSN e devolvemos ao trabalhador o turno de seis horas, coisa que muitos duvidavam. Conquistamos aumento real em quase todos os acordos coletivos, além de benefícios, por exemplo, as melhores PLRs ou PPRs no setor automotivo, e uma bonificação extra que varia entre $60 \%$ e $75 \%$. Também conquistamos a implantação do cartão alimentação, plano de saúde, e outros benefícios em empresas que não praticavam (Chapa 1, 2014, p. 1)

O trecho acima pertence ao material de campanha da chapa que se elegeu, em 2014, para o terceiro mandato consecutivo desde 2006. Trata-se do período no qual Renato Soares, 56 anos, esteve na presidência do sindicato. Note-se, portanto, que, a despeito de todo o apelo à "parceria", essa diretoria, vinculada à Força Sindical, busca se mostrar concomitantemente fiel ao arsenal simbólico edificado pelo SMSF ao longo dos conflagrados anos 1980. Isso ocorre, inclusive, no nível mais prático e conflitivo possível: na reconquista da jornada 
de seis horas, bandeira principal da emblemática greve de 1988 e dispositivo que a CSN privatizada busca empedernidamente desfazer.

Portanto, é possível perceber uma postura dúplice do sindicato frente à mobilidade dos capitais: se o sindicato faz questão de propagandear o quanto a sua busca por parceria seria benigna para atrair empreendimentos automobilísticos (o que veremos no item cinco), por outro lado, busca denunciar, sistematicamente, as ameaças de deslocamentos vinculadas ao setor siderúrgico, mais tradicionalmente implantado na região. No que diz respeito especificamente à CSN, essa postura mais confrontacionista por parte do sindicato tem raízes na tradição da qual Soares se orgulha de fazer parte, desde os tempos de "cipeiro"13 da Companhia Siderúrgica Nacional, e que ainda reverbera entre trabalhadores aposentados com poder de voto sindical. O jogo pesado do presidente da CSN, Benjamin Steinbruch, com a cidade também concorre para a belicosidade sindical. Soares ${ }^{14}$ considera que o empresário "não gosta mesmo de Volta Redonda e nem do pessoal daqui". Por isso, reconhece que "[...] com a CSN a gente joga mais pesado que com as montadoras". O contexto de crise de 2008, quando Steinbruch demitiu 1.200 trabalhadores, conturbou a relação de modo definitivo. A questão do turno de seis horas é decisiva para a manutenção desse padrão conflitivo:

Ele queria que eu entregasse o turno [de seis horas] para ele [...]. Eu consegui [recuperar o turno de seis horas] em $2007^{15}$ e ele queria acabar com a bonificação de férias, que na lei é 33\% e a CSN paga 70\%. Já foi $91 \%$, só que, na gestão anterior, a pelegada entregou. O que ele queria naquela crise de 2008? Queria

${ }^{13}$ Membro da CIPA- Comissão Interna de Prevenção de Acidentes.

${ }^{14}$ Informação cedida pelo Ex-presidente do SMSF (20062014) e atual vice-presidente, jan./fev. 2015.

${ }^{15}$ A gestão do sindicalista Perrut (2001-2005) dera continuidade à política de parceria que estava estabelecida com a CSN desde o contexto da privatização. Dentre os direitos "negociados" com a CSN estava a renúncia do turno de seis horas em Acordos Coletivos. Assim como seu antecessor, Luizinho Rodrigues, Perrut era da Força Sindical. Durante o mandato, porém, mudaria para CỦT, após ter sido acusado de corrupção por seus próprios companheiros de direção. aproveitar para acabar com a bonificação de férias e ganhar o turno sem pagar a propina para o pessoal: você pode fazer o turno de $8 \mathrm{~h}$ desde que você dê um valor pra rapaziada! Ele mandou 1.200 pessoas embora. Ele esticou a corda e eu estiquei. Até chegar e falar "vou mandar embora mais 1800". Eu falei "dane-se, fecha a usina”. Eu combati a entrega de direitos e agora vou ser conivente? [...] Ou você flexibiliza e entrega os direitos do trabalhador, do pouco que sobrou, ou então você banca as demissões. Eu banquei as demissões e depois no governo, com a pressão do Lula, voltou todo mundo. Voltaram os 1.200.

Num caso explícito de ativismo contra a mobilidade potencial da CSN, o sindicato se contrapôs à tentativa de Steinbruch de comprar a Companhia Siderúrgica do Atlântico (CSA) na extrema zona oeste carioca. ${ }^{16}$ Temia-se o deslocamento de investimentos e empregos para a nova aquisição. Soares chegou a se reunir com o Banco Nacional de Desenvolvimento Econômico e Social para tratar do assunto, bem como escreveu um manifesto público contra a eventual compra.

O Benjamin queria comprar a CSA com financiamento do BNDES, com juros baixíssimos e longa carência para pagar. Eu falei: já que ele vai comprar - eu não era contra - eu fui para o BNDES e na assessoria da Dilma. Minha preocupação era o governo financiar, a CSN comprar e desativar as áreas que fazem placas aqui e, em nome de não ter mais poluição, trazer as placas de lá para cá para serem laminadas [...] Então eu comecei a trabalhar antes que a coisa acontecesse. Se ele vai comprar, assina um termo de compromisso: 'vou comprar a CSA, assumo o compromisso de não desativar nada em Volta Redonda'. Pronto, acabou!

No setor siderúrgico, o sindicato atuou para a dissuasão do deslocamento ou enxugamento de empregos em mais um caso. A empresa envolvida era a Votorantim. O deslocamento dar-se-ia dentro da própria área de influência do sindicato (de Barra Mansa para Resende), mas podendo provocar perdas líquidas de postos de trabalho e prejuízo a trabalhadores mais experientes. Soares conta que havia aprendido

${ }^{16}$ A CSA fica situada no bairro de Santa Cruz, na cidade do Rio de Janeiro, mas repercute mormente no território de Itaguaí (RJ). 
sobre essa estratégia empresarial observando a CSN fechar setores da gigantesca Unidade Presidente Vargas, em Volta Redonda, ao criar a siderúrgica Galvasud, em Porto Real:

\footnotetext{
A Votorantim fez uma empresa nova em Resende, que faz a mesma coisa que a de Barra Mansa. A CSN fez também uma empresa de aço longo [Galvasud] e ela começou a desativar equipamentos [em Volta Redonda] com uns argumentos meio furados. Eu falei: vou dar uma gritaria aí [no caso Votorantim], para chamar a atenção da sociedade antes que o barco afunde. Fui para a imprensa, chamei umas autoridades de Barra Mansa para a reunião e falei 'vocês têm que tomar cuidado lá, porque a de Resende tem equipamento novo [...] a Votorantim era chamada de museu. Para eles desativarem isso aqui, de pouquinho em pouquinho, não custa muito não [...]'. Eu fiz aquilo ali para poder antecipar os fatos. Aí eles pararam [de demitir em Barra Mansa], porque a sociedade se virou [...] Eu não vou cair no erro da privatização da CSN: a turma que era contra ficou nisso e acabou que o Benjamim levou a usina e as terras [de propriedade da CSN] todinhas. Por quê? Falta de visão estratégica.
}

\section{O SINDICATO E OS GREENFIELDS AUTOMOBILÍSTICOS: insulamento competitivo e desdém pelo classismo}

Nenhuma grande empresa vai se instalar em lugares onde os sindicatos tenham atitudes radicais [...]. A Nissan poderia ter ficado em São José dos Pinhais (PR), onde sua coligada Renault tem fábrica, mas é bem possível que uma greve de 37 dias feita pelo sindicato de lá na Volkswagen tenha pesado contra essa decisão (Diário do Vale, 2012).

A fala acima foi emitida por Renato Soares quando se anunciava que Resende havia vencido a "batalha" pela Nissan. Pode-se ver claramente que sua gestão deu continuidade à prática, padronizada pelo SMSF desde meados da década de 1990, de se mostrar como um sindicato de relações "ganha-ganha" com montadoras. Essa postura havia começado na gestão de Luiz Rodrigues, a primeira da Força Sindical que colaborou com a privatização e
}

com a chegada da Volkswagen/MAN (Abreu; Beynon; Ramalho, 2006). O que há de mais interessante na autopromoção de Soares contra o "insensato" sindicato de São José dos Pinhais é que ambos pertencem à Força Sindical. Essa convergência formal definitivamente não aglutina as duas entidades sindicais. Soares nos contou, em entrevista, a relação azedada entre as entidades:

Essa política nossa acabou por nos criar problema com outros sindicatos. Porque eu não vou ser o paladino da salvação. Qual foi a minha política nesses oito anos de presidente? Apertar as empresas, mas até certo ponto, se não vai espanar o parafuso. [...] O pessoal do Paraná perdeu a Nissan para nós. Por quê? Os caras pedem, em PLR, 25 ou 30 mil [...] a Volks [MAN] virou líder do mercado por que nós deixamos eles fazerem 44 horas semanais, sendo que a maioria das montadoras luta para fazer 40 horas. Só nisso já fica competitivo. Eles pagam 2 mil de abono para os trabalhadores para continuar 44 horas. Ela é uma das únicas. É ela e a Iveco em Sete Lagoas $[\ldots]$.

O depoimento de Soares à pesquisa foi pródigo nos exemplos de sua política de "não apertar demais" as empresas. Num deles, descreveu uma briga com o departamento jurídico da Volkswagen/MAN: “[...] doutor, aqui a questão não é só jurídica, é política. O senhor sabia que a MAN é uma das poucas montadoras que faz 44h semanais, deixando ela competitiva? Você sabia que a PLR da MAN chega a ser metade do que se paga em São Paulo, no Paraná e Campinas ?" Depois, comentou sua participação na atração da Jaguar/Land Rover para Itatiaia, formalizada em 2014:

Eu dando palestra com os ingleses da Land Rover e com o governador. Eu falando, por causa do público que estava lá, tudo empresário: 'nós não vemos os empresários como inimigos. Nós vemos os empresários como parceiros para a geração de riqueza e emprego pra nossa região. Então o sindicato tem uma postura não radicalismo; ele tem uma relação de sentar, conversar e tirar o melhor possível para os dois lados’. Então essa foi a política que eu implantei aqui na região.

O presidente do sindicato não é um ino- 
cente-útil no jogo da chantagem locacional por investimentos. Ele tem plena percepção, como se vê na citação abaixo, que as montadoras criam jogos competitivos entre as bases sindicais de suas distintas plantas, como forma de conquistar melhores posições nos mercados de veículos. O SMSF tem justamente pautado sua performance pelo conhecimento e pela observação atenta desse cenário, pensando geoestrategicamente à maneira das empresas, isto é, avaliando suas possibilidades de ser atacado ou de conquistar novas posições.

A MAN faz 12 anos que é líder de mercado de caminhões. Mas a Mercedes está na cola dela. E agora a Mercedes tem instrumento para pressionar o sindicato lá em São Bernardo: a fábrica que ela tem lá em Juiz de Fora, onde ela fazia van, foi transformada numa fábrica de caminhões e de ônibus, com a mão de obra de lá, que é mais barata. Então, ou o sindicato lá flexibiliza algumas coisas, ou então ela leva o investimento para Juiz de Fora. E a MAN, sabendo disso, entrou de uma maneira agressiva: 'vou mandar 1600 pessoas embora [...]' [ameaça feita em janeiro de 2015].

Não há dúvidas de que o SMSF tem conseguido representar sua base sindical de modo satisfatório, o que atesta a continuidade do grupo dirigente desde 2006 (a eleição de 2014 foi vencida em primeiro turno, com $60 \%$ dos votos). Ocorre que a contraface desse contexto, marcado por combatividade e atuação na cena pública regional, tem sido o ceticismo ante qualquer ação interlocal e intersindical, tendo o sindicato abandonado mesmo a ideia de "classe trabalhadora". Explicitamente perguntado sobre a existência dessa categoria, Soares afirmou seu ceticismo na existência de trabalhadores atuando de modo politicamente unificado sob o capitalismo. O fim da União Soviética, para ele, seria uma das provas. Tal declaração seria de pouco interesse se isolada do comportamento padrão do SMSF. Ocorre que a pergunta só surgiu após o sindicalista narrar um fato: ele havia desprestigiado uma conversa com sindicalistas da Nissan dos Estados Unidos, sob a alegação de que o SMSF "disputa os empregos contra eles":
Eles chamaram a nós e muitos sindicalistas para ir na cidade onde fica a Nissan nos EUA. Eu falei para a pessoa: é o seguinte, não vou não [...] Eu falei: é uma competição de investimento. [...] A Nissan quis parar aqui por quê? Porque aqui o governo estadual deu incentivo fiscal, o governo municipal deu terras de graça, logística boa e o sindicato é mais flexível [...] Não adianta ter um resultado a curto prazo bom que, a médio ou longo prazo, ia ferrar com os trabalhadores e a região. Haja vista o que a [central sindical] CONLUTAS fez em São José dos Campos: apertou demais, a General Motors tirou Zafira, Meriva, o Corsa. Parou de produzir. O Corsa Especial levou para a argentina. Era um sindicato combativo o pessoal da CONLUTAS? Era, e daí? A opinião ficou contra eles. Investimento que era pra ser feito lá - por causa da logística legal - levaram pra Gravataí e para São Paulo.

Outro momento ilustrativo do desdém pelo classismo veio quando o assunto foi o contrato nacional do setor automotivo. Recapitulemos do que se tratava: em 1999, ainda no contexto da implantação da Ford na Bahia e a concomitante ameaça de demissão em massa nas plantas paulistas da empresa, o sindicato dos metalúrgicos do ABC propôs um contrato nacional para a indústria automobilística. Nele, ficaria estipulado um piso salarial para todo o território nacional, como forma de impedir que a descentralização dos investimentos tivesse como fito o rebaixamento de padrões laborais já conquistados. Com a recusa das montadoras, os metalúrgicos passaram a promover o "festival nacional de greves", com algum sucesso em termos salariais, o que aglutinou Força Sindical e CUT. Em 2013, a ideia do contrato nacional tinha voltado ao debate público, por conta de uma nova onda de expansão das montadoras no país. Soares, porém, se mostrou cético quanto à questão:

Esse negócio era para quê? Se a Volks for lá pro Amazonas vai ter que pagar o mesmo salário que paga aqui. Só que isso é utopia. A CUT queria fazer isso aí. Para nós, se for fazer é interessante, mas esse contrato nacional coletivo é negociado com a cúpula, você ia ser boi de piranha aqui embaixo [...] Por que o comunismo perdeu a disputa ideológica com o capitalismo? Se você tem um carro que vale 
mil, eu quero um que valha dois mil, o outro vai querer que vá valer três. É o ser humano.

Para o metalúrgico, mesmo as centrais sindicais não teriam importância estratégica na elevação geral das condições de vida dos assalariados. Segundo ele, as centrais sindicais se equivalem. São apenas grupos concorrentes que lutam por recursos. Quando conquistou a diretoria pela primeira vez, em 2006, o fez independentemente das centrais, ${ }^{17}$ entrando no embate eleitoral com sua trajetória de cipista e contando com o desgaste da gestão anterior, acusada de corrução. O retorno do SMSF à Força Sindical foi motivado, durante a gestão de Soares, apenas por razões instrumentais: ele admite ter aderido à central para impedir que ela continuasse disputando as eleições sindicais no Sul Fluminense pela oposição, com significativo aporte de recursos. O "plano A" da Força Sindical foi, segundo ele, fraudar as eleições de 2010. Após o malogro, a central teria incentivado o desmembramento territorial da base dos metalúrgicos da região, a partir da formação do Sindicato dos Metalúrgicos das Agulhas Negras, que abarcaria Resende, Itatiaia e Porto Real. Soares acabaria filiando seu sindicato à Força Sindical, com o propósito de neutralizar seus adversários locais, num lance análogo às fusões e aquisições de empresas ڤิ̀ que correm o mundo:

\footnotetext{
遂 Nós filiamos à Força em 2010. Não que tenhamos amores pela Força: é que ela tentou desmembrar o sindicato nosso aqui [...] A Força tentou fraudar na eleição [de 2010], mas eu descobri [...] contratamos 40 seguranças, eles vieram de São Paulo. Quando eles viram e perceberam, recuaram [...] tomamos posse e entramos na Força por questões estratégicas. Apesar de que central sindical hoje é tudo meia dúzia. Eles estão mais interessados em aderir sindicato para ter participação do imposto sindical.

17 “Ah, nós não éramos [ligados a centrais] coisa nenhuma. Aliás, quem nos ajudou foi a $C D B$ [...] os caras fizeram a maior pressão pra eu me filiar quando eles criaram a CDB. Só que o negócio era o seguinte: como eu vou me filiar à $C D B$ se vai ter uma eleição aqui e ela não tem estrutura e suporte pra eu ganhar uma eleição? Aí viria a Força com o seu peso pesado e eu ia perder a eleição".
}

\section{CONSIDERAÇÕES FINAIS}

O Sindicato dos Metalúrgicos do Sul Fluminense tem sido potente em termos de representação direta de seus afiliados, mostrando capacidade de produzir alianças em favor do emprego e da renda na região, mas em paralelo a uma intensa naturalização de um viés competitivo contra outras regiões e bases sindicais. Se o neoliberalismo pode ser definido pela indução da forma empresa a todos os agentes individuais e coletivos (Foucault, 2008), pode-se dizer que atuação do SMSF está intensivamente conformada a um contexto como esse.

Pereira (2012) demonstrou que o comportamento histórico do SMSF pode ser significativamente explicado pelo perfil de cada presidente da entidade. A presente pesquisa converge para tal análise. De toda maneira, o objetivo do artigo foi conectar esse personalismo ao cenário mais amplo de incremento da mobilidade dos capitais e da consagração de um poder púbico empresarial e competitivo. Os resultados do Sul Fluminense reafirmam o quanto essas duas variáveis têm sido detonadoras de significativas mudanças na contemporaneidade, em função do poder que assumem em reordenar as relações entre economia, Estado e ativismo coletivo em perspectiva neoliberal. As posturas do presidente do sindicato precisam ser situadas nesse contexto, na medida em que se trata de um ex-membro da CUT, que teve formação socialista ${ }^{18}$ e que viveu a era de ouro do Novo Sindicalismo em Volta Redonda.

Espera-se que os achados da pesquisa contribuam para o debate público em torno das escalas espaciais pertinentes à ação sindical num contexto de capitais móveis. Sabe-se que hoje proliferam os discursos de valorização da ação "local" ou "regional" e sobre a necessidade de os sindicatos serem colaborativos com as empresas. Os resultados da pesquisa,

${ }^{18} \mathrm{O}$ entrevistado pediu que os detalhes sobre isso não fossem divulgados. 
porém, apontam para a necessidade de renovação das práticas de solidariedade interlocal entre trabalhadores organizados, visando a eliminar o que Markusen (1995) chama de "componente soma zero": situações em que o crescimento de uma região se dá às expensas de outra; empregos bem remunerados se tornam a contraparte de baixos salários em outras localidades. E poderíamos acrescentar: os sindicatos mais "competitivos" nada mais fazem que concorrer por empregos que antes pertenciam a trabalhadores de outras localidades, jogando para baixo os padrões de remuneração e de condições de trabalho conquistadas pelos sindicatos mais organizados.

Como provocação final, perceba-se como o contexto de capitalismo móvel e a neoliberalização do poder público vêm realizando o velho sonho do corporativismo varguista, ao forjarem sindicatos de "colaboração de classes", defensivos e afeitos mais à prestação de serviços (jurídicos, de saúde, lazer etc.) do que às ações unificadas. Não era outro o pensamento corporativista dos anos 1930, que prescrevia sindicatos atomizados por unidade territorial e por setor econômico, vedando a existência das centrais sindicais. $\mathrm{O}$ imposto sindical, esse velho inimigo do Novo Sindicalismo que resistiu ao tempo, acaba tendo enorme parcela de responsabilidade em atomizar territorial e setorialmente a ação sindical. Testemunham-se, inusitadamente, os efeitos despolitizantes do imposto sindical corporativista serem restabelecidos no contexto neoliberal de fragmentação e competição. Há interpretações mais parcimoniosas quanto à herança corporativista, que consideram que o imposto sindical teria resolvido o problema de coordenação da ação coletiva dos trabalhadores. Porém, essa "solução" depende do que chamamos de "problema”. Numa concepção corporativa e particularista a resolução está dada. No entanto, se considerarmos os dilemas do sindicalismo em contexto de globalização, as alianças intraclassitas ainda estão rarefeitas. É o que podem atestar os trabalhadores da Nissan no Missis- sipi ou os demitidos da GM de São José dos Campos.

Recebido para publicação em 28 de junho de 2016 Aceito em 10 de agosto de 2017

\section{REFERÊNCIAS}

ABREU, A.; BEYNON, H.; RAMALHO, J. R. "A fábrica dos sonhos" da Volkswagen. In: RAMALHO, J. R.; SANTANA, M. A. (Org.). Trabalho e desenvolvimento regional: efeitos sociais da indústria automobilística no Rio de Janeiro. Rio de Janeiro: Mauad X, 2006. p. 71-90.

BOLTANSKI, L.; CHIAPELLO, E. O novo espírito do capitalismo. São Paulo: Martins Fontes, 2009.

BOURDIEU, P. Rethinking the state: on the genesis and structure of the bureaucratic field. Sociological Theory,[S.l.], Wiley-Blackwell, v.12, n.1, p. 1-19, mar. 1994.

BOURDIEU, P. Contrafogos: táticas para enfrentara invasão neoliberal, Tradução de Lucy Magalhães, Rio de Janeiro, Jorge Zahar Editor, 1998.

CARDOSO, A. M. A Nova Face da Indústria Automobilística ou a tese da convergência revisitada. In: ARDOSO, A.; COVARRUBIAS, A. (Org.). A indústria automobilística nas Américas. Belo Horizonte: Editora UFMG, 2006. p. 79-112.

CARDOSO, I. C. C. Desenvolvimento, Expansão Urbana e Segregação Espacial: desafios do desenvolvimento urbano de Resende a partir do Século XXI. In: RAMALHO, J. FORTES, A. (Org.). Desenvolvimento, trabalho e cidadania: Baixada e Sul Fluminense. Rio de Janeiro: 7 Letras, 2012. p. $125-160$.

CASTEL, R. As metamorfoses da questão social. 4. ed. Petrópolis: Vozes, 1998.

CHAPA 1. Material de campanha. Volta Redonda. 2014.

CHENAIS, F. "A nova economia": uma conjuntura própria à potência econômica estadunidense. In: CHENAIS, F. et al. Uma Nova Fase do Capitalismo? São Paulo: Xamã, 2003. p. 43-70.

CORDEIRO, M. Ser trabalhador flexível e competente: um olhar sobre família, trabalho e educação. In: RAMALHO, J. R.; FORTES, A. (Org.). Desenvolvimento, trabalho e cidadania: Baixada e Sul Fluminense. Rio de Janeiro: 7 Letras, 2012.

DURÃO, M. No ABC Fluminense, Negócios de R\$ 4,7. $O$ Globo, Rio de Janeiro, 22 out. 2011. Disponível em: < http:// oglobo.globo.com/economia/no-abc-fluminensenegociosde-47-bi-2897520 > . Acesso em: 22 jul. 2014.

ECONOMIA. Diário do Vale, Volta Redonda, Volta Redonda, 9 de jul. 2013. p. 8.

FRANCISCO, E. Desafios para Organização dos Trabalhadores Metalúrgicos no Sul Fluminense: uma década de experiências. In: RAMALHO, J. R.; FORTES, A. (Org.). Desenvolvimento, trabalho e cidadania: Baixada e Sul Fluminense. Rio de Janeiro: 7 Letras, 2012. p. 161-180.

FOUCAULT, M. Nascimento da biopolítica. São Paulo: Martins Fontes, 2008.

GÓES, F. Volta Redonda Teme pelos Efeitos da Compra da CSA. Valor Econômico, Rio de Janeiro, 11 mar. 2013. Disponível em: <http://www.valor.com.br/ empresas/3039164/volta-redonda-teme-pelos-efeitos-dacompra-da-csa >. Acesso em: 11 dez. 2014. 
GRACIOLLI, E. J. Privatização da CSN: da luta de classes á parceria. São Paulo: Expressão Popular, 2007.

HARVEY, D. Do gerenciamento ao empresariamento: a transformação na administração urbana no capitalismo tardio. Espaço e Debates, São Paulo, v .16, n. 38, p. 48-64, 1996.

HARVEY, D. O novo imperialismo. 13. ed. São Paulo: Loyola, 2005.

LIMA, R. J. C. Empresariado local, Indústria automobilística e a Construação de Porto Real. Inः RAMALHO, J. R.; SANTANA, M. A. (Org.). Trabalho e desenvolvimento regional: efeitos sociais da indústria automobilística no Rio de Janeiro. Rio de Janeiro: Mauad X, 2006.

LIMA, R. J. C. A reinvenção de uma cidade industrial: volta redonda e o pós-privatização da Companhia Siderúrgica Nacional. 2010. 277 f. Tese (Doutorado em Sociologia e Antropologia) - Instituto de Filosofia e Ciências Sociais, Universidade Federal do Rio de Janeiro, Rio de Janeiro 2010 .

MARKUSEN, A. Áreas de atração de investimentos em um espaço econômico cambiante: uma tipologia de distritos industriais. Nova Economia, Belo Horizonte, v. 5, n. 2, p. 9-44, dez. 1995

NISSAN inaugura fábrica com meta de atingir $5 \%$ do mercado nacional. Diário do Vale, Volta Redonda, 16 abr. 2014. Caderno Especial Nissan, p 2. Disponível em: https:// issuu.com/diariodovale/docs/7276_-_diario_-_quartafeira_-_16.0. Acesso em: 16 jun. 2016.

NOVA fábrica da Nissan em Resende terá investimentos de R\$ 2,6 bilhões. Diário do Vale, Volta Redonda, 9 mar. 2013. Disponível em: <http://diariodovale.uol. com.br/noticias/1,70401, Nova-fabrica-da-Nissanem-Resende-tera-investimentos-de-R \$-26-bilhoes. html\#axzz2NBvLibe5 >. Acesso em: 16 jun. 2016.

OLIVEIRA, F. Os Direitos do antivalor. Petrópolis: Vozes, 1998.

OLIVEIRA, R.V. Sindicalismo e democracia no Brasil: do novo sindicalismo ao sindicato cidadão. São Paulo: Annablume: FAPESP, 2011.

OLMOS, M. No jogo dos carros, governo do Rio quer o segundo lugar. Valor Econômico, 05 mar.2013. Especial, p. A16.

PEREIRA, S. M. Sindicalismo e Privatização: o caso da ^ Companhia Siderúrgica Nacional. São Luís: EDUFMA 。 FAPEMA, 2012.

$\therefore$ PEREIRA, L. Jaguar Land Rover inaugura fábrica em Itatiaia (RJ) para produzir Evoque. Portal G1, Rio de Janeiro, 14 . jun. 2016. Disponível em: <http://g1.globo.com/carros/ ส] noticia/2016/06/jaguar-land-rover-inaugura-fabrica-em$\Sigma$ itatiaia-rj-para-produzir-evoque.html $>$. Acesso em: 16 余 jun. 2016.

¿ RAMALHO, J. R. Fórum Demissão Zero: crise e ação ô coletiva no Sul Fluminense. In: RAMALHO, J. R.; FORTES,

$\therefore$ A. (Org.). Desenvolvimento, trabalho e cidadania: Baixada 2 e Sul Fluminense. Rio de Janeiro: 7 Letras, 2012. p. 225$\infty 246$.
RAMALHO, J. R.; SANTANA, M. A.; MAÇAIRA, J. P. Trabalho e Sindicato na PSA Peugeot Citroën do Brasil. In: RAMALHO, J. R.; SANTANA, M. (Org.). Trabalho e desenvolvimento regional: efeitos sociais da indústria automobilística no Rio de Janeiro. Rio de Janeiro: Mauad X, 2006. p. 227-237.

ROLLI, C.; MIOTO, R. Funcionários da Nissan dos EUA fazem protesto no salão do automóvel. Folha de S. Paulo, 31 out. 2014.

ROCHA, L. O Novo Discurso da Qualificação profissional na Indústria Automobilística do Rio de Janeiro. In: RAMALHO, J. R.; SANTANA, M. (Org.). Trabalho e desenvolvimento regional: efeitos sociais da indústria automobilística no Rio de Janeiro. Rio de Janeiro: Mauad X, 2006. p. 137-158.

SANTANA, M. Trabalhadores e Política no Sul Fluminense: a experiência de Volta Redonda nos anos 1980. In: RAMALHO, J. SANTANA, M. (Org.). In: RAMALHO, J. R.; SANTANA, M. (Org.). Trabalho e desenvolvimento regional: efeitos sociais da indústria automobilística no Rio de Janeiro. Rio de Janeiro: Mauad X, 2006. p. 159-174.

SANTOS, R. O Sul Fluminense em Questão. In: RODRIGUES, I. RAMALHO, J. (Org.). Trabalho e sindicato em antigos e novos territórios produtivos. São Paulo: Annablume, 2007. p. 89-118.

SILVA, C. Montadoras vão investir R\$ 30 bilhões no sudeste. O Estado de São Paulo, São Paulo, 13 nov. 2013. Economia e Negócios. Disponível em: http://economia. estadao.com.br/noticias/geral,montadoras-vao-investir-r30-bilhoes-no-sudeste,170068e. Acesso em: mar. 2015.

SMSF. Boletim 9 de novembro: informativo semanal do sindicato dos metalúrgicos da Região Sul Fluminense. Volta Redonda: SMSF, 2010-2015. Disponível em: http://www.sindmetalsf.org.br/sind boletins. asp?menu=comunicacao\&submenu=boletins. Acesso: $23 \mathrm{abr}$ 2015.

SOROCABA vence disputa pela nova fábrica da Toyota. Manutencão e Suprimentos, [São Paulo], 23 jul. 2008. Disponível em: <http://www.manutencaoesuprimentos. com.br/conteudo/1628-sorocaba-vence-disputa-pelanova-fabrica-da-toyota/> . Acesso em:30 Jan. 2015.

SOUZA, C. Pelo espaço da cidade: aspectos da vida e do conflito urbano e Volta Redonda. 1992. 197 f. Dissertação (Mestrado em Planejamento Urbano e Regional) Instituto de Pesquisa e Planejamento Urbano e Regional, Universidade Federal do Rio de Janeiro, Rio de Janeiro 1992.

VILAS BOAS, B. No rastro das multinacionais, estrangeiros criam ‘Torre de Babel'. O Globo, Rio de Janeiro, 21 jul. 2013. Disponível em: <https://oglobo.globo.com/economia/norastro-das-multinacionais-estrangeiros-criam-torre-debabel-9113866 >. Acesso em: 23 fev. 2015.

WACQUANT, L. Três etapas para uma antropologia histórica do Neoliberalismo realmente existente. Caderno $C R H$, Salvador, v. 25, n. 26, p. 505-518, 2012. 


\section{SYNDICALISM ADJUSTED TO THE NEOLIBERALISM: the steel workers of the southern region of Rio de Janeiro state}

\section{Gustavo Bezerra}

This study investigated the path of the Metallurgical Trade Union of the Southern region of Rio de Janeiro State in a period of accomplishments, which allowed us to verify the adoption of neoliberal patterns of behavior even in the absence of precariousness processes. This article presents a trade union scenario marked by combativeness and by being active in the public scene of the region, but also corrupted by skepticism about any interregional and inter trade union action. It is a powerful union in terms of direct representation of its affiliates, but it naturalizes its competitive bias against other regions and unions. A central hypothesis in this study was that trade union action had been strongly reconfigured by two factors: the environment of capital mobility and the process of neoliberal normalization of the ways of governing the territory. Empirical evidence was collected from interviews with trade union leaders, academic productions about the region, union bulletins and journalistic material.

KeYworDs: Sociology. Urban and regional planning. Public administration.

\section{LE SYNDICALISME NORMALISE AU NEOLIBERALISME: les métallurgistes du sud de Rio de Janeiro}

Gustavo Bezerra

La recherche a étudié l'histoire du Syndicat des métallurgistes du Sud de l'État de Rio de Janeiro dans une période de conquêtes, ce qui a permis de vérifier l'adoption de modèles de comportements néolibéraux même en l'absence de processus de précarisation. Le résultat présente un scénario syndical marqué par la combativité et l'action sur la scène publique de la région, mais aussi par le scepticisme envers toute action inter locale et intersyndicale. Il s'agit d'un syndicat puissant en termes de représentation directe de ses membres, mais qui naturalise son parti pris concurrentiel contre d'autres régions et bases syndicales. On a soulevé l'hypothèse selon laquelle l'action syndicale aurait été fortement reconfigurée par deux facteurs: l'environnement de mobilité des capitaux et le processus de normalisation néolibérale des manières de gouverner le territoire. Des preuves empiriques ont été recueillies à partir d'entretiens avec les leaders ouvriers, des recherches universitaires sur la région, les bulletins syndicaux et le matériel journalistique.

Mots-CLÉs: Sociologie. Planification urbaine et régionale. Administration publique.

Gustavo Bezerra-Doutor em sociologia pelo Instituto deEstudos Sociais e Políticos (IESP) da Universidade do Estado do Rio de Janeiro (UERJ). Professor adjunto do Instituto de Pesquisa e Planejamento Urbano e Regional da Universidade Federal do Rio de Janeiro (IPPUR-UFRJ). Áreas de pesquisa: Estado, questão social e redemocratização no Brasil; sociologia econômica; sociologia do trabalho; poder e escalas espaciais; conflitos socioambientais; Estado e empresários; sociologia do Direito e dos sistemas de justiça. Integra os grupos de pesquisa Estado, Trabalho, Território e Natureza (ETTERN-IPPUR-UFRJ) e Grupo de Estudos em Desenvolvimento Econômico do Sul Fluminense (GEDESF-UFF). Publicações recentes: Trajetórias pós-salariais: versatilidade laboral e exploração em rede em duas experiências. Revista da ABET (Impresso), v. 12, p. 12-28, 2014; Inserción económica internacional y 'resolución negociada' de conflictos ambientales en América Latina. EURE (Santiago. Impresa), v. 36, p. 27-47, 2010. 
